\title{
Coalizões em educação no Brasil: relação com o governo e influência sobre o Plano de Desenvolvimento da Educação (PDE)
}

\author{
Lara Elena Ramos Simielli \\ Fundação Getulio Vargas (FGV-EAESP)
}

\begin{abstract}
Atualmente, duas coalizões lutam pela melhoria da qualidade da educação no Brasil: a Campanha Nacional pelo Direito à Educação e o Todos pela Educação. Essas duas coalizões diferenciam-se dos movimentos históricos por sua capacidade de agregar atores provenientes de instituições governamentais e não governamentais, de diversos níveis, que possuem valores e crenças comuns em uma aliança única, aproximando-se do conceito de coalizões advocatórias proposto por Sabatier e Jenkins-Smith (1993). Apesar da bandeira comum, elas possuem origens, composições, metas e formas de atuação completamente diferentes - a relação com o governo é um dos pontos que mais as diferencia. O lançamento do Plano de Desenvolvimento da Educação (PDE), com uma das medidas intitulada "Plano de Metas Compromisso Todos pela Educação", gerou questionamentos com relação à similaridade dos nomes entre um plano de governo e uma das coalizões. Neste artigo, apresentaremos as duas coalizões e a relação de ambas com o governo, utilizando o PDE como estudo de caso.
\end{abstract}

Palavras-chave: coalizões advocatórias; política pública em educação; Plano de Desenvolvimento da Educação (PDE); Campanha Nacional pelo Direito à Educação; Todos pela Educação (TPE).

Coaliciones de educación en Brasil: relación con el gobierno e influencia sobre el Plan de Desarrollo de la Educación (PDE)

En la actualidad, dos coaliciones tienen el liderazgo en la disputa por la mejora de la educación en Brasil: "Campanha Nacional pelo Direito à Educação" y "Todos pela Educação". Ambas coaliciones son distintas a los movimientos históricos debido a su capacidad de unir actores provenientes de instituciones gubernamentales y no gubernamentales de distintos niveles, con valores y creencias comunes en una alianza única; acercándose así al concepto de advocacy coalitions propuesto por Sabatier y Jenkins-Smith (1993). A pesar del objetivo final común, tienen orígenes, composición y formas de actuar completamente diferentes; la relación con el gobierno es uno de los puntos que más las diferencia. La puesta en marcha del Plan de Desarrollo de la Educación (PDE) con una de sus medidas llamada "Plano de Metas Compromisso Todos pela Educação" generó dudas acerca de la similitud de nombres entre una de las coaliciones y un plan gubernamental. En este artículo, presentamos a las dos coaliciones y su relación con el gobierno, usando el PDE como caso de estudio.

Palabras clave: advocacy coalitions; política pública para la educación; Plan de Desarrollo de la Educación (PDE); Campaña Nacional por el Derecho a la Educación; Todos por la Educación (TPE).

Artigo recebido em 14 nov. 2011 e aceito em 15 fev. 2013.

Rev. Adm. Pública - Rio de Janeiro 47(3):567-586, maio/jun. 2013 
Educational coalitions in Brazil: relationship with the government and influence over the Educational Development Plan (PDE)

Nowadays, the two most prominent coalitions in the Brazilian educational context are the "Campanha Nacional pelo Direito à Educação" and the "Todos pela Educação". These two coalitions differ from the historical movements due to their capacity to aggregate various actors from government and nongovernment organizations, and from different hierarchical levels in a single alliance, due to shared values and beliefs - close to the concept of advocacy coalitions proposed by Sabatier and Jenkins-Smith (1993). Despite of sharing the same final goal, however, the two coalitions have different origins, compositions, financial sources and strategies. Their relationship with the government is one of the topics that most differentiates them, which will be analyzed using the launch of the Educational Development Plan (PDE) as a case study, due to the similarity between the name of one of the coalitions and one of the objectives proposed by the PDE. In this article, we will present the two coalitions and their relationship with the government, using the PDE as an example.

Keywords: advocacy coalitions; educational public policy; Educational Development Plan (PDE); National Campaign on the Right to Education; All for Education.

\section{Introdução}

Atualmente, veem-se diversas iniciativas visando à melhoria da qualidade da educação no Brasil, provenientes do governo, do setor privado e das associações do chamado Terceiro Setor. Entre elas, porém, sobressaem-se duas grandes coalizões que merecem este destaque por terem maior abrangência em relação às demais e por serem responsáveis por articular atores provenientes de diversas instituições, governamentais e não governamentais, sob uma mesma bandeira: a Campanha Nacional pelo Direito à Educação e o Todos pela Educação (Simielli, 2008).

Alianças, movimentos e organizações em defesa da educação pública não representam uma novidade no cenário brasileiro. O destaque do momento atual reside no fato de que há uma aparente formação de coalizões, aproximando-as do conceito de coalizão advocatória proposto por Sabatier e Jenkins-Smith (1993:25) para designar a junção de "atores públicos e privados, provenientes de diversas instituições e níveis governamentais, que dividem um conjunto de crenças e valores comuns e que buscam manipular as regras, orçamentos e recursos humanos governamentais visando a atingir seus objetivos no longo prazo".

Apesar do objetivo de longo prazo em comum, qual seja, a melhoria da qualidade da educação brasileira, estas duas coalizões possuem origens, composições, fontes de recursos, metas e formas de atuação completamente diferentes. A relação com o governo é um dos pontos que mais as diferencia - e um dos que tem causado maior discussão.

Um dos pontos principais do debate acerca da relação destas coalizões com o governo está no lançamento do Plano de Desenvolvimento da Educação (PDE). Em março de 2007, o Ministério da Educação lançou o PDE, que apresentou um conjunto de projetos para a melhoria da educação no país. A principal novidade do PDE foi a introdução do Índice de Desen- 
volvimento da Educação Básica (Ideb), ${ }^{1}$ que prevê que, até 2022, o Brasil alcance a nota seis, atual média dos países pertencentes à OCDE. Em pronunciamento sobre o PDE, no dia oficial de seu lançamento, o ex-presidente da República, Luiz Inácio Lula da Silva, afirmou:

O Plano de Desenvolvimento da Educação, que tenho a alegria de lançar neste momento, traz em seu arcabouço poderosos instrumentos de aperfeiçoamento de gestão, financiamento, conteúdo, método, participação federativa e participação cidadã, capazes de promover profundas mudanças na nossa educação pública. Eu o anuncio como o Plano mais abrangente já concebido neste País para melhorar a qualidade do sistema público e para promover a abertura de oportunidades iguais em educação. Eu vejo nele o início do novo século da educação no Brasil (...). (Brasil, 2007)

Um dos pontos de discussão está no fato de que uma das medidas do PDE foi intitulada "Plano de Metas Compromisso Todos pela Educação", prevendo a adesão voluntária dos municípios a algumas diretrizes e o cumprimento das metas projetadas pelo Ideb por parte das escolas das redes municipais e estaduais até 2022. Essa medida causou questionamentos com relação à similaridade dos nomes entre um plano de governo e uma das coalizões.

Esta semelhança entre os nomes provocou desconforto entre alguns atores, principalmente entre aqueles ligados à Campanha Nacional pelo Direito à Educação, que entenderam que foram excluídos do processo de elaboração do PDE. Para os membros do TPE, porém, o fato de o ministro ter participado das reuniões deste movimento desde o seu início tornou a adoção do nome uma consequência natural do alinhamento de esforços e da busca conjunta pelo alcance das metas. Entre as repercussões do caso, houve inclusive a troca do nome do Todos pela Educação, que, no início, se denominava Compromisso Todos pela Educação.

Neste artigo iremos apresentar as duas coalizões e refletir sobre esta coincidência de nomes entre uma das medidas do PDE com uma das coalizões, dentro do contexto mais amplo da análise do relacionamento de ambas com o governo.

\section{Metodologia de pesquisa²}

O objeto de estudo da pesquisa foram as duas coalizões que lutam por uma educação pública no Brasil: a Campanha Nacional pelo Direito à Educação e o Todos pela Educação (TPE). Os

\footnotetext{
${ }^{1}$ O Ideb é calculado com base em dois fatores que interferem na qualidade do ensino: as taxas de aprovação e as médias de desempenho dos alunos nas avaliações nacionais. Esta combinação resulta em uma média para cada escola, município, estado e para o país, que varia de 0 a 10 (Inep, 2011).

${ }^{2}$ Este artigo tem como base a dissertação de mestrado intitulada Coalizões em educação no Brasil: a pluralização da sociedade civil na luta pela melhoria da educação pública, defendida por Simielli (2008) na FGV-EAESP, sob orientação do prof. dr. Mario Aquino Alves. O levantamento de dados e as entrevistas foram realizados em 2007 e 2008, com revisão das principais informações e dados em 2011, 2012 e 2013.
} 
dois atores foram analisados com relação a um aspecto específico: a relação com o governo, com enfoque na influência sobre o Plano de Desenvolvimento da Educação (PDE).

Para o entendimento das duas coalizões, trabalhamos com uma etapa inicial referente ao levantamento de dados e, posteriormente, com um estudo de caso múltiplo, de caráter exploratório e descritivo (Simielli, 2008). Na etapa inicial, foram analisados materiais de divulgação da Campanha Nacional pelo Direito à Educação e do TPE (impressos e digitais), além de informações veiculadas na mídia.

Realizamos entrevistas a partir de um roteiro básico, porque o objetivo era fazer uma comparação entre as duas coalizões e a falta de uma estruturação mínima poderia prejudicar esta análise (Ritchie e Lewis, 2003). As entrevistas foram semiestruturadas, com base em perguntas-chave.

Foram entrevistadas, além do corpo diretivo e de membros das duas coalizões, pessoas de destaque na área educacional externa a elas. A escolha dos entrevistados deu-se de forma não aleatória - selecionamos aqueles que consideramos ser os mais relevantes ao nosso estudo e que trariam maiores contribuições à pesquisa. ${ }^{3}$ Nossa amostra foi escolhida com base em um determinado propósito - analisar em profundidade duas aparentes coalizões em educação no país - , método conhecido como "amostra baseada em critério ou em propósito" (Mason e Patton, apud Ritchie e Lewis, 2003).

Foram entrevistados 20 atores, em conversas com duração aproximada de uma hora:

a) Membros da Campanha Nacional pelo Direito à Educação: Daniel Cara e Iracema Nascimento (coordenadores), Elizabete Ramos (Comitê de Pernambuco e Centro de Cultura Luiz Freire), Ester Rizzi e Sandra Faria (na época, representantes da Fundação Abrinq), Roberto Franklin de Leão (presidente da Confederação Nacional dos Trabalhadores em Educação - CNTE) e Sergio Haddad (Ação Educativa).

b) Membros do TPE: Ana Maria Diniz (Instituto Pão de Açúcar), Luis Norberto Pascoal (Fundação DPaschoal), Milú Vilella (Instituto Itaú Cultural e Instituto Faça Parte), Mozart Neves Ramos (na época, presidente executivo do TPE), Priscila Cruz (diretora executiva do TPE) e Viviane Senna (Instituto Ayrton Senna).

c) Atores externos: Carlos Ramiro de Castro (na época, presidente da Apeoesp), Elie Ghanem (FE-USP), Fernando Rosetti (Grupo de Institutos, Fundações e Empresas — Gife), Maria Auxiliadora Rezende (Conselho Nacional de Secretários em Educação - Consed), Maria da Gloria Gohn (Unicamp e Uninove), Mário Sérgio Cortella (PUC-SP) e Romualdo Portela (FE-USP).

Todas as citações foram enviadas aos entrevistados, visando garantir que nada fosse colocado sem o consentimento de todos os envolvidos. As descrições da Campanha Nacional

\footnotetext{
${ }^{3}$ Os coordenadores da Campanha e do TPE ajudaram-nos a selecionar as pessoas que seriam entrevistadas, tanto internas quanto externas às coalizões.
} 
pelo Direito à Educação e do TPE também foram revisadas pelas respectivas coordenações, refletindo o que aparece nos materiais de divulgação e a posição de seus coordenadores (Simielli, 2008).

\section{Atores centrais à formulação de políticas públicas}

A literatura que aborda os atores considerados centrais à formulação das políticas públicas teve, historicamente, divisão em duas grandes correntes (Grindle e Thomas, 1991). A primeira delas tem na sociedade e nos grupos de interesse o centro das análises, entendendo que são esses atores que definem as políticas públicas, considerando-se seu poder de influência sobre os atores estatais. Para esta abordagem, o Estado aparece como um ator praticamente neutro, receptor dos interesses encontrados na sociedade e responsável pela implementação das vontades dos grupos hegemônicos. A segunda delas refere-se aos autores e estudiosos que situam a atuação do Estado no centro da análise, entendendo que este é o principal ator na definição das políticas públicas e que, embora a sociedade civil tenha alguma influência sobre as decisões estatais, é o Estado quem irá determinar as escolhas finais. São, portanto, os gestores públicos e as organizações estatais o centro desta corrente.

Estudos mais recentes têm destacado a importância do equilíbrio entre estes dois atores — a sociedade e o Estado - , ampliando o debate e tornando-o mais complexo. No entendimento dessas novas abordagens, tanto os grupos de interesse da sociedade quanto os atores estatais são importantes para a definição das políticas públicas, devendo ambos merecer papéis centrais nas análises (Evans, Rueschemeyer e Skocpol, 1985; Grindle e Thomas, 1991; Marques, 1997; Migdal, Kohli e Shue, 1994; Sabatier, 1991; Sabatier e Jenkins-Smith, 1993).

Assim, abordagens mais recentes entendem que, se, por um lado, a sociedade tem maneiras de se organizar em grupos e organizações para defender determinados interesses e tentar influenciar o Estado, este, por sua vez, é quem irá desenhar e implementar as políticas e, portanto, possui o poder final de decisão. O resultado das políticas públicas passa a ser o resultado da combinação de interesses dos atores estatais e não estatais.

Dentro desta corrente inserem-se abordagens como a teoria das coalizões advocatórias (advocacy coalition framework), a teoria neoinstitucionalista e a teoria do state-in-society. Escolheremos focar apenas a teoria das coalizões advocatórias por conta do relacionamento direto com o que será tratado no restante do artigo.

\subsection{Teoria das coalizões advocatórias}

A teoria desenvolvida por Sabatier e Jenkins-Smith (1993) aponta que a mudança nas políticas públicas ao longo do tempo é o resultado de três processos: da interação entre coalizões advocatórias internamente ao subsistema da política pública; das mudanças externas ao subsistema; e dos efeitos dos parâmetros estáveis do sistema, como a estrutura social e as regras 
constitucionais. Ou seja, as mudanças são o resultado tanto das mudanças internas ao subsistema (variáveis endógenas) quanto das mudanças externas a ele (variáveis exógenas).

Os atores centrais ao processo são as coalizões advocatórias, definidas como a junção de “atores públicos e privados, provenientes de diversas instituições e níveis governamentais, que dividem um conjunto de crenças e valores comuns e que buscam manipular as regras, orçamentos e recursos humanos governamentais visando a atingir seus objetivos no longo prazo" (Sabatier e Jenkins-Smith, 1993:25).

Há, de acordo com os autores, entre duas e quatro coalizões importantes atuando em determinado setor — nem todas as pessoas e instituições pertencentes ao setor, porém, estarão inseridas em uma coalizão ou compartilharão dos mesmos valores e interesses.

De acordo com este modelo, assim, a definição da agenda, as possíveis soluções, a escolha de uma determinada alternativa e a implementação da mesma passam a ser entendidas como resultado dos interesses de uma coalizão dominante.

O poder de dominação de uma coalizão e sua habilidade em implementar suas vontades e interesses dependerão diretamente dos recursos que ela possui, o que inclui recursos financeiros, conhecimento técnico, número de apoiadores e membros, e autoridade legal (Sabatier e Jenkins-Smith, 1993). Esses recursos não são estáticos ao longo do tempo e ao mudar a posse dos mesmos mudam-se, necessariamente, o poder e a influência exercidos pelas coalizões.

Para que haja mudanças profundas em uma determinada política pública, portanto, é preciso que haja a substituição de uma coalizão dominante por outra. Isso ocorrerá como produto da combinação de perturbações externas ao sistema, como mudanças nas condições socioeconômicas, e do aproveitamento dessas mudanças externas pelas coalizões anteriormente minoritárias (Sabatier e Jenkins-Smith, 1993). Ou seja, mesmo que os eventos externos produzam oportunidades para mudanças, essas oportunidades devem ser adequadamente aproveitadas pelas coalizões.

As variáveis exógenas, compostas pelos eventos externos e pelos parâmetros estáveis do sistema, afetam os obstáculos e oportunidades disponíveis (Sabatier e Jenkins-Smith, 1993). Os eventos externos ao subsistema compreendem as mudanças no ambiente socioeconômico, as mudanças na coalizão que está no governo e os impactos provenientes de decisões políticas tomadas em outros subsistemas. Já os parâmetros estáveis são os atributos e características de uma determinada política pública, a distribuição natural dos recursos, valores socioculturais e estrutura social, e as regras (ou estrutura constitucional) que regem o sistema.

Para os autores, a mudança nos parâmetros estáveis é bastante difícil e requer o trabalho de uma coalizão por mais de uma década. Os eventos externos, por outro lado, são mais dinâmicos e podem alterar o cenário em que se insere uma política pública em apenas alguns anos.

Um dos aspectos mais importantes deste modelo é o papel do conhecimento gerado no processo da política pública, capaz de alterar os pensamentos e as intenções de comportamento. O aprendizado gerado é fundamental porque poderá redefinir o sistema de valores das coalizões e a estratégia utilizada por elas, causando uma reformulação interna ao subsistema (Sabatier e Jenkins-Smith, 1993). 


\section{Descrição das coalizões contemporâneas em educação}

Alianças e organizações de luta em defesa da educação pública não são uma novidade no cenário brasileiro. Movimentos em defesa da educação pública existem desde o início do século XX, como o Manifesto dos Pioneiros da Educação Nova (1932), a Campanha pela Defesa da Escola Pública (1959) e o Fórum Nacional em Defesa da Escola Pública (1987).

O que diferencia estas duas coalizões dos movimentos históricos, porém, é a aparente formação de coalizões, capazes de agregar atores provenientes de instituições governamentais e não governamentais, de diversos níveis, que possuem valores e crenças comuns em uma aliança única. O momento atual, assim, diferencia-se das iniciativas anteriores, entre outras razões, pelo formato e estrutura organizacional adotados - enquanto atualmente vê-se a formação de duas coalizões, as manifestações e movimentos históricos devem ser entendidos e classificados como movimentos sociais, por serem: a) menos institucionalizados e formais do que outros espaços coletivos (Cohen, 2003; Gohn, 2006), b) dirigidos, de modo não hierárquico, por um ator social (Munck, 1997); e c) constituídos por atores carentes de recursos (Tarrow, apud Gohn, 2006).

O cenário atual, formado pelas duas coalizões, confirma o que foi proposto por Sabatier e Jenkins-Smith (1993) de que há, geralmente, entre duas e quatro coalizões importantes atuando em determinado setor. A presença destas duas coalizões, porém, não significa dizer que todas as pessoas e entidades que atuam neste setor estão necessariamente inseridas em uma ou outra coalizão - há importantes organizações que não pertencem nem à Campanha nem ao TPE.

Apesar de classificarmos as duas iniciativas como coalizões, a Campanha Nacional pelo Direito à Educação, por seu próprio ciclo de vida, aproxima-se mais do conceito de coalizão advocatória, por conta da sua forma de atuação e de um sistema de valores e crenças mais definido e difundido entre seus membros - seu sistema de valores e crenças está mais consolidado do que no TPE, o que transparece em um discurso mais unificado e forte. Além disso, a Campanha pode ser considerada uma aliança mais consolidada, com maior abrangência e atuação no cenário atual, estando presente em mais estados e contando com o apoio de atores mais heterogêneos. Seu foco de atuação, por fim, está especificamente voltado à advocacy.

O TPE, por sua vez, é uma coalizão ainda em construção, contando com muitos elementos que fazem com que não possamos considerá-la como uma coalizão advocatória no sentido estrito, com destaque para a centralização das ações em figuras-chave, a inexistência de um consenso ideológico e técnico entre seus membros e a ausência da intenção de fazer advocacy. O consenso existe apenas em relação às metas, que são metas genéricas - diferentemente da Campanha, que tem um consenso em relação a pontos específicos, como o papel da educação.

Merece destaque na atuação do TPE, porém, a inclusão de um ator que, historicamente, não esteve envolvido na luta pela melhoria da qualidade da educação: os empresários. Neste sentido, vemos a participação do TPE nesta luta como o ponto de inflexão em relação ao nosso passado, responsável por ter incluído a presença destes novos atores na discussão sobre a educação e na luta pela sua melhoria. 
A seguir apresentamos as duas coalizões para depois analisarmos o relacionamento de ambas com o governo, com foco especial no lançamento do PDE.

\subsection{A Campanha Nacional pelo Direito à Educação ${ }^{4}$}

A Campanha Nacional pelo Direito à Educação representa diversas entidades e organizações não governamentais do Brasil e está ligada à Campanha Global pela Educação e à Campanha Latino-Americana e do Caribe pelo Direito à Educação.

A Campanha foi criada em 1999 e surgiu da articulação de diversas entidades e organizações não governamentais que há anos lutavam pela garantia dos direitos à educação, como a Ação Educativa, a Confederação Nacional dos Trabalhadores em Educação (CNTE) e a Fundação Abrinq.

A Campanha define-se como

uma rede que articula mais de 200 grupos e entidades distribuídas por todo o país, incluindo movimentos sociais, sindicatos, organizações não governamentais nacionais e internacionais, fundações, grupos universitários, estudantis, juvenis e comunitários, além de centenas de cidadãos que acreditam na construção de um país justo e sustentável por meio da oferta de uma educação pública de qualidade. ${ }^{5}$

Composta por um comitê diretivo nacional e por comitês regionais em diversos estados, faz com que se autocaracterize como "a articulação mais ampla e plural no campo da educação básica no Brasil". Fazem parte do comitê diretivo 10 instituições: Ação Educativa, ActionAid Brasil, Centro de Cultura Luiz Freire, Centro de Defesa da Criança e do Adolescente do Ceará (Cedeca - CE), Confederação Nacional dos Trabalhadores em Educação (CNTE), Fundação Abrinq, Movimento Interfóruns de Educação Infantil do Brasil (Mieib), Movimento dos Trabalhadores Rurais Sem Terra (MST), União Nacional dos Conselhos Municipais de Educação (Uncme) e União Nacional dos Dirigentes Municipais de Educação (Undime).

Os comitês regionais, por sua vez, estão presentes em 18 estados brasileiros e no Distrito Federal, funcionando em entidades ou organizações que participam da Campanha. É importante salientar que "em função das particularidades locais, cada Comitê possui uma estrutura diferente e atua de uma determinada forma".

Além dos membros, há diversos colaboradores, muitos deles ligados a universidades e centros de pesquisa, "que possuem um grande acúmulo na área da Educação e contribuem de

\footnotetext{
${ }^{4}$ As citações que aparecem nesta seção foram retiradas de materiais de divulgação e do site da Campanha Nacional pelo Direito à Educação (Disponível em: <www.campanhaeducacao.org.br>. Acesso em: 10 jan. 2013).

${ }^{5}$ Disponível em: <www.campanhaeducacao.org.br>. Acesso em: 10 jan. 2013.
} 
diferentes formas com a Campanha" ${ }^{\prime}$ por meio de estudos, produção de artigos e realização de palestras e oficinas.

A Campanha tem suas ações e projetos financiados pelos seguintes parceiros: ActionAid, Fondo Regional de la Sociedad Civil para la Educación (Fresce), Instituto C\&A, Open Society Foundations, Unicef (Fundo das Nações Unidas para a Infância), Coordenadoria Ecumênica de Serviços (Cese) e Fundação Abrinq/Save the Children. Durante alguns anos, recebeu também recursos da Plan Brasil, Oxfam, Novib e Organização das Nações Unidas para a Educação, a Ciência e a Cultura (Unesco).

De maneira sintética, seus principais focos de ação são:

1) construção de um sistema nacional de ensino democrático e capaz de promover acesso equitativo à educação de qualidade; 2) financiamento público adequado; 3) valorização das e dos profissionais de educação; 4) gestão democrática; 5) determinação de processos participativos de avaliação. ${ }^{7}$

São sete as estratégias de ação da Campanha: articulação institucional, pressão sobre autoridades, mobilização popular, produção de conhecimento, comunicação, formação de atores sociais e justiciabilidade. Mais do que pesquisar e informar, porém, entende-se que "uma Campanha de âmbito nacional só será bem-sucedida se for capaz de articular diversos setores na luta por objetivos comuns", ${ }^{8}$ salientando a importância da mobilização institucional e da mobilização social.

\subsection{Todos pela Educação (TPE) ${ }^{9}$}

O Todos pela Educação (TPE) define-se como uma aliança dos esforços da sociedade civil, da iniciativa privada e dos gestores públicos, que tem como objetivo final "mobilizar e comprometer o Brasil para que até 2022 todas as crianças e jovens tenham uma educação básica de qualidade", ${ }^{10}$ entendendo-se, neste sentido, como um movimento portador de um "projeto de nação, com a participação de toda a sociedade brasileira".

Conforme divulgado, a grande diferença do TPE em relação a outros projetos e movimentos voltados para a melhoria da qualidade da educação está em três pontos. Em primeiro lugar, o projeto diferencia-se pela "abrangência, alcance e horizonte de longo prazo", considerando-se que é um projeto nacional, organizado pelas "mais representativas forças da socieda-

\footnotetext{
${ }^{6}$ Material de divulgação da campanha.

${ }^{7}$ Disponível em: <www.campanhaeducacao.org.br>. Acesso em: 10 jan. 2013.

${ }^{8}$ Material de divulgação da campanha.

${ }^{9}$ As citações que aparecem nesta seção foram retiradas de materiais de divulgação e do site do Todos pela Educação (Disponível em: <www.todospelaeducacao.org.br>. Acesso em: 12 jan. 2013).

${ }^{10}$ Material de divulgação. Todas as citações seguintes também foram retiradas de materiais de divulgação.
} 
de civil (não por uma empresa, uma fundação ou um governo)", estando aberto à participação de todos os interessados, e responsável por fixar um horizonte de 16 anos até o cumprimento das metas. Em segundo lugar, aponta-se para o fato de ser uma "ação permanente", e não um movimento isolado ou pontual, que pretende atuar ao lado do governo e da sociedade civil. Por fim, há o estabelecimento de cinco metas focadas "no resultado e não no processo", que serão monitoradas por meio da "coleta sistemática de dados e da análise de séries históricas" e que poderão ser acompanhados pela população.

O TPE foi oficialmente lançado no dia 6 de setembro de 2006, no Museu do Ipiranga (SP), escolhido por ter sido o local da proclamação da Independência em 1822. Para eles, o ano e local são emblemáticos a partir da ideia de que a real independência do país só virá quando todos os cidadãos tiverem acesso a uma educação de qualidade.

A ideia do movimento, contudo, começou um ano antes, em junho de 2005, durante uma reunião no Projac entre o Instituto Faça Parte, representantes do programa Amigos da Escola, da Rede Globo, e a então presidente da União Nacional dos Dirigentes Municipais de Educação (Undime), Maria do Pilar Lacerda.

A partir de então, um grupo liderado por Milú Villela, presidente do Instituto Faça Parte, começou a se reunir a fim de discutir esta ideia. Esse grupo foi aumentando com o tempo, ganhando a adesão principalmente de pessoas ligadas a institutos, fundações e organizações sociais e da iniciativa privada, além de atores governamentais, principalmente ligados ao Ministério da Educação (MEC), ao Conselho Nacional de Secretários de Educação (Consed) e à União Nacional dos Dirigentes Municipais de Educação (Undime).

O fato de o MEC ter participado desde o início da fundação do TPE é muito importante. Como divulgado no site do movimento, o PDE teve como "principal ação" o "Plano de Metas Compromisso Todos pela Educação", que "foi assim chamado em reconhecimento à sintonia existente entre as cinco metas defendidas pelo movimento e os objetivos do Plano proposto pelo MEC". Para eles,

assim como o TPE acredita que apenas com objetivos claros e a busca incansável de resultados é possível melhorar a qualidade da Educação no Brasil, o MEC introduzia, entre outras medidas, de forma inédita, uma política de metas e indicadores de qualidade como condição para o repasse de recursos a estados e municípios.

A coincidência de nomes entre uma das medidas do PDE e esta coalizão, porém, fez com que esta, fundada com o nome de Compromisso Todos pela Educação, passasse a denominarse apenas Todos pela Educação (TPE).

O TPE atualmente conta com um Conselho de Governança, presidido por Jorge Gerdau Johannpeter e composto por 20 pessoas: Ana Maria dos Santos Diniz, Antonio Jacinto Matias, Beatriz Bier Johannpeter, Cesar Callegari, Daniel Feffer, Danilo Santos de Miranda, Denise Aguiar Alvarez, Fabio Coletti Barbosa, Fernão Bracher, José Francisco Soares, José Paulo Soares Martins, José Roberto Marinho, Luís Norberto Pascoal, Luiz Paulo Saade Montenegro, 
Maria Lucia Meirelles Reis, Milú Villela, Mozart Neves Ramos, Ricardo Young da Silva, Viviane Senna e Wanda Engel Aduan.

A maioria das pessoas que pertencem ao Conselho de Governança representa empresas, institutos e fundações que mantêm o TPE. São mantenedores do TPE: Banco Santander, DPaschoal, Instituto Unibanco, Fundação Itaú Social, Gerdau, Instituto Camargo Correa, Fundação Bradesco, Suzano Papel e Celulose, Itaú BBA e Faber-Castell.

Além dos mantenedores, o TPE conta ainda com apoiadores e parcerias estratégicas. São parceiros: Grupo ABC, Rede Globo, Instituto Ayrton Senna, DM9DDB, Rede Energia, Gol Linhas Aéreas, Amics, Fundação Victor Civita, McKinsey\&Company, Microsoft, Fundação Santillana, Instituto Paulo Montenegro, Instituto HSBC Solidariedade, Futura, Amigos da Escola, Instituto Natura, Saraiva, Fundação Telefônica, BID, Patri Políticas Públicas.

Para o TPE, a aliança formada pelo Estado, pelo mundo empresarial e pelas organizações do Terceiro Setor é importante porque cada um pode contribuir de uma maneira específica. O Estado "tem o dever e a obrigação de ser o detentor dos fins universais", atendendo a todos os cidadãos. O mundo empresarial "destaca-se pela sua capacidade de fazer acontecer (lógica dos meios) com eficiência, eficácia e efetividade". Por fim, as organizações sociais ou entidades ligadas ao Terceiro Setor "caracterizam-se pela sua sensibilidade, criatividade e espírito de luta".

O TPE trabalha com cinco metas, que foram estabelecidas com base no entendimento de que "um compromisso efetivo por uma Educação de qualidade requer metas claras, a serem alcançadas em prazo determinado". Para eles, é fundamental o estabelecimento de metas para diferenciar o TPE das tentativas históricas de luta pela educação ao afirmar que "planos e documentos de intenção se multiplicam na história da educação brasileira, muitas vezes sem trazer explícitos os objetivos a serem perseguidos ou o tempo para seu cumprimento". São elas:

v Meta 1 - Toda criança e jovem de 4 a 17 anos na escola

v Meta 2 - Toda criança plenamente alfabetizada até os 8 anos

v Meta 3 - Todo aluno com aprendizado adequado à sua série

、 Meta 4 - Todo jovem de 19 anos com o Ensino Médio concluído

、 Meta 5 - Investimento em educação ampliado e bem gerido

Para o alcance das metas, criou-se um tripé de ações estratégicas: a) a influência na demanda, por meio da comunicação; b) a influência na oferta, por meio da articulação com outras entidades e com as esferas governamentais; e c) a influência na qualidade e quantidade das informações sobre o tema, por meio do acompanhamento e da divulgação de dados, pesquisas e informações relacionadas à educação e às cinco metas. 


\section{Interface com o governo: postura das coalizões e lançamento do Plano de Desenvolvimento da Educação (PDE)}

A relação entre as duas coalizões e o governo deve ser entendida à luz do momento histórico em que elas foram criadas. A Campanha foi criada em 1999, como um movimento nacional ligado à Campanha Global pela Educação e à Campanha Latino-Americana e do Caribe, representando a junção de diversas organizações não governamentais que lutavam há anos pelo cumprimento dos direitos estabelecidos pela Constituição de 1988, num contexto de contestação e crítica ao governo e de combate aos vetos do Plano Nacional de Educação (PNE). O TPE, por sua vez, foi criado em 2006, de maneira colaborativa com o governo, que fez parte, desde o início, de sua concepção e elaboração.

A diferente composição interna também faz com que a interface entre as coalizões e o governo se dê de forma diferente, considerando-se o perfil e as formas históricas de atuação de seus membros. A Campanha, neste sentido, é vista, internamente, como uma coalizão responsável por adotar uma postura crítica em relação ao governo, mas com o objetivo final de propor novos caminhos ou novos olhares.

Para Daniel Cara, coordenador geral da Campanha, ela "tem uma relação com o poder público de crítica, de interlocução crítica"; a mesma visão de Iracema Nascimento, coordenadora executiva da Campanha, que entende que a postura desta coalizão em relação ao governo envolve "autonomia, crítica, no sentido construtivo, e proposição", porque, para ela, "não basta só criticar", o que só é possível porque "hoje em dia, há mais espaço para proposição".

Para Roberto Leão, presidente da CNTE, a "Campanha tem uma relação de movimento social com o governo, como uma articulação da sociedade civil lutando pela educação". Esta relação "se dá por meio de diálogos diretos — através de audiências — e manifestações públicas". Ou seja, a Campanha tem uma relação "mais de questionamento".

Já o TPE é visto por seus membros como um movimento que existe não para "cobrar o Executivo", "para apontar os erros e acertos", mas que deve agir como um "facilitador". A adoção de uma postura crítica dá lugar a uma relação de colaboração — visão reforçada tanto por seus membros quanto por atores externos. Para alguns membros, a aliança com o governo deve ser enfatizada por conta do seu alcance, ou seja, porque só dá para "chegar na ponta se houver articulação com o governo".

Esta visão é reforçada por atores externos, que veem o TPE como um movimento de articulação com o Estado, de parceria com o setor público. O contexto em que o TPE foi criado e o perfil de seus membros, assim como no caso da Campanha, são fundamentais para este posicionamento, porque o movimento nasce num momento em que é valorizada esta visão de "o que podemos fazer juntos" - uma característica menos presente na Campanha.

Alguns membros da Campanha entendem que o TPE não tem "o propósito de exigir do Estado, mas de somar forças", o que pode ser ilustrado pelo fato de o próprio MEC fazer parte do TPE, o que não deixa de ser, para alguns, "em certa medida, esquizofrênico". Uma forte crítica ao TPE, além disso, reside no fato de que, apesar de ter uma interlocução direta com o 
governo via mídia, por conta do poder econômico representado, o movimento não conta com mobilização popular, como indicado por atores pertencentes à Campanha.

Iracema Nascimento aponta para o fato de que o MEC não participa da Campanha, como participa do TPE — destacando "momentos de concordância e confronto entre a Campanha e o MEC". Já a participação da Undime na Campanha é vista, por ela, como positiva para a própria Undime, dado que "na pauta do Fundeb, sem a Campanha, a Undime não emplacaria uma série de propostas".

Com relação à participação das instituições governamentais nas coalizões, Romualdo Portela, professor titular da Faculdade de Educação da USP, aponta que "uma coisa é a Undime ir aos eventos, e outra é a indução das políticas". Para ele, isso acontece tanto no TPE quanto na Campanha, em que a adesão é superestrutural. Parece-nos, entretanto, que a relação vai além disso, tanto na Campanha quanto no TPE.

Na comparação da relação entre os dois movimentos com os diferentes poderes, não há um consenso, mas a tendência geral é enxergar a Campanha como mais próxima do Legislativo, enquanto o TPE como mais próximo ao Executivo.

\subsection{Lançamento do "Plano de Metas Compromisso Todos pela Educação" no Plano de Desenvolvimento da Educação (PDE)}

Um dos principais pontos no que se refere à relação entre os dois movimentos e o governo esteve no lançamento do PDE, em março de 2007. O PDE, entre as inúmeras medidas, lançou o "Plano de Metas Compromisso Todos pela Educação", prevendo a adesão voluntária dos municípios a algumas diretrizes e o cumprimento das metas projetadas pelo Ideb por parte das escolas das redes municipais e estaduais de ensino até o ano de 2022. Os municípios poderiam aderir ao programa por meio de um "Termo de Adesão do Plano de Metas Compromisso Todos pela Educação", disponível no site do MEC, e teriam direito a assistência técnica e apoio financeiro, devendo garantir, em contrapartida, o alcance das diretrizes e metas do Ideb.

Para analisarmos esta questão, porém, precisamos entender o contexto em que o PDE foi lançado. Como bem trabalhado por Malini (2009), o PDE foi um plano lançado às pressas, dentro de um contexto político em que o ministro Fernando Haddad, na época há aproximadamente um ano no cargo, foi pressionado a apresentar um novo plano para a educação, sob o risco de perder o cargo. O objetivo do então presidente Lula com essa demanda foi, além de receber um novo plano para a educação, tentar blindar o MEC de interferências políticas, garantindo um perfil mais técnico à pasta. Para Malini (2009), "este estado de coisas parece ter definido o ritmo e a natureza da formulação do Plano de Desenvolvimento da Educação", situação que motivou o ministro a buscar soluções rápidas para a elaboração do plano — um cenário que privilegiou a busca por projetos e metas claros e prontos, mais facilmente encontrados no TPE e em institutos e fundações ligados a ele, como o Instituto Ayrton Senna e a Fundação Itaú Social. 
Neste sentido, as diretrizes do TPE e as cinco metas ajudaram na elaboração do PDE, que surgiu como um agregado de propostas e não como um plano bem documentado e elaborado. O PDE surge, assim, como um agregado de projetos e planos em muitos casos já existentes, fato observado por muitos dos entrevistados.

Romualdo Portela, professor da Faculdade de Educação da USP, colocou que "tirando o Ideb, não há novidade no plano", chegando a questionar-se se "o PDE é um plano ou uma justaposição de medidas".

A falta de um documento que organize o plano incomodou, assim como a Romualdo, a muitos dos entrevistados. Mesmo assim, ele aponta melhoras neste sentido, frisando o fato de, em outubro de 2007, o Ministério ter divulgado "um texto que procurava dar coesão política ao plano". Ainda assim, em sua opinião, "isso parece vir mais como consequência das críticas do que de um projeto estruturado". Da mesma forma, "no final do ano, o plano passou a enfatizar mais a gestão, com mecanismos que tentavam induzir mudança nos municípios, sobretudo nos pequenos, com Ideb mais baixo".

Entre os membros da Campanha, de maneira geral, houve um forte sentimento de exclusão do processo de debate e formulação do PDE. Para Elizabete Ramos, coordenadora do Comitê de Pernambuco da Campanha e pesquisadora do Centro de Cultura Luiz Freire, "o PDE surgiu sem um processo de debate".

Para Iracema Nascimento, o nome Compromisso Todos pela Educação no PDE "foi um susto", e fez com que a Campanha questionasse o lançamento de "um plano de governo vinculado a um setor". Ela finaliza dizendo que "havendo ou não interferência, a utilização do nome é equivocada e não é bom para a autonomia de um plano de Estado". As metas do PDE, por sua vez, são difíceis de serem cumpridas, justamente porque são de governo e não de Estado, ou seja, "entrando outra força político-partidária, é difícil ter continuidade", o que gera "pouca esperança de que as metas sejam cumpridas".

Sandra Faria e Ester Rizzi (representantes, na época, da Fundação Abrinq) entendem que o fato de ter sido o mesmo nome se mostrou "complicado e constrangedor". Para elas, gerou uma confusão não saudável para a sociedade civil. Foi por causa de o MEC ter aderido às metas do TPE por meio do PDE que elas entendem que a "Campanha adotou uma postura mais crítica" - situação que pode mudar e se inverter ao longo do tempo.

Para Iracema Nascimento, apesar de haver rumores de que o TPE não gostou do MEC ter usado o mesmo nome, é sabido que o "Ministro Fernando Haddad participou desde o início do TPE", que "estava envolvido na sua elaboração". Mais do que isso, Elizabete Ramos sinaliza que, "quando o MEC coloca o nome Compromisso Todos pela Educação e coloca o foco na educação profissionalizante, está mostrando a sua orientação".

Roberto Leão, presidente da CNTE, entende que foi uma escolha infeliz do governo ter optado pelo mesmo nome para o PDE. Para ele, o MEC não discutiu com ninguém o plano, "não discutiu com a Campanha, com o CNTE e com outras entidades da sociedade civil", "mas discutiu com o TPE". A ênfase nas metas e na avaliação demonstra isso. O que deveria ter sido feito, em sua opinião, seria uma Conferência Nacional de Educação e "a partir das deliberações, ter elaborado o plano". O governo, porém, escolheu o "caminho contrário". 
Elizabete Ramos tem a mesma opinião, afirmando que o governo, ao fazer um plano de educação, deveria instituir "espaços públicos e democráticos de debate". Para ela, se "vai fazer um plano de governo, então vamos criar um espaço de debate com a sociedade para discutir, para ouvir o que a sociedade precisa e apresentar as propostas", mas que seja "um espaço público aberto ao público e à diversidade, incluindo os empresários, o MST, os índios, as mulheres, todo mundo".

O Ministério, na opinião de Leão, juntou programas já existentes e lançou o PDE. Depois de lançado é que o MEC buscou discutir, organizando um seminário, realizado em outubro de 2007 (sete meses depois do lançamento), para discussão com a CNTE e convidados.

Alguns membros da Campanha, porém, discordam desta visão. Para Daniel Cara, por exemplo, o PDE foi um "grande drible político de Haddad no TPE, que acabou sendo menos um interlocutor e mais um propagador das ideias do MEC". Isso porque, "na época em que foi anunciado, o PDE foi veiculado na grande imprensa como um plano construído junto com o TPE". Com o passar do tempo, quando o governo foi aprimorando e divulgando - com enorme atraso - o texto de seu novo plano, "percebemos que nossa pressão deu certo, e que o PDE está - no espectro da identidade política - mais próximo à Campanha do que ao TPE, especialmente porque não inclui instrumentos absurdos como a punição de profissionais, ponto defendido por muitos atores integrantes do TPE". Para ele, "o Haddad, em uma extensa audiência com a Coordenação e o Comitê Diretivo da Campanha, reconheceu o protagonismo político da rede, mas reiterou que não iria abrir mão da hegemonia na opinião pública". É por esta "fala sincera" que Cara avalia "que quando ele colocou o nome de "Plano de Metas Compromisso Todos pela Educação’ no principal programa do PDE, procurou fazer um gesto simpático a este grupo". Foi por conta disso que "como resultado, ganhou toda a força midiática desse movimento, que inclui empresários proprietários dos grandes veículos de mídia, além de empresas que são as grandes anunciantes", o que, "no âmbito do poder de comunicação pública”, “o TPE pode se traduzir em uma combinação bombástica”. Para Cara, esta busca pela parceria e interlocução com as duas coalizões "deve-se à própria história política de Fernando Haddad", que:

Apesar de ser filiado ao PT há muitos anos, possuir no passado forte interlocução com os movimentos sociais e ter sido um intelectual de matriz marxista, teve em sua experiência pública na gestão Marta Suplicy e no Governo Lula uma relação bem estabelecida com os setores empresariais, aos quais em uma entrevista à revista Época ele atribuiu — erroneamente, na minha opinião - o rótulo de classe dirigente. Essa aproximação bivalente é normal, faz parte da liturgia dos cargos públicos, mas deve ser tratada com muito cuidado e habilidade política. Nesse sentido, considero a aproximação do MEC com o Todos pela Educação exagerada e equivocada, de ambos os lados.

Além do nome, a escolha do governo de pedir a adesão voluntária dos municípios também foi criticada. Para Elizabete Ramos, "da maneira como os planos estão chegando ao município, é um acordo entre o MEC e o prefeito", e "não é um acordo entre o prefeito e o MEC 
que irá mudar o processo, que fará o professor mudar a sua aula". Para Iracema, o pedido de adesão às metas do PDE foi inadequado: "seria absurdo pedir para os municípios aderirem à Campanha, como pediram adesão ao Compromisso Todos pela Educação". Para ela, depois "tentaram explicar que eram duas coisas diferentes", que "uma coisa era o movimento e outra o plano do governo", mas "quem fez a confusão foi o MEC e quem deixou foi o TPE. Devem ter achado que era uma boa ideia", afirmou.

Os membros do TPE, por sua vez, viram esta semelhança de maneira positiva, mas cautelosa. Mozart Ramos afirma que o TPE não ajudou a escrever o PDE. Mas, para ele, considerando-se que o MEC participou ativamente da fundação do TPE, as metas vinham sendo debatidas desde 2005 e, portanto, "seria muito estranho que o ministro criasse um PDE muito diferente do que vinha sendo debatido". Mozart reconhece, porém, que esta questão do nome causou desconforto nos demais movimentos.

Priscila reitera a visão de Mozart ao afirmar que "souberam do PDE 15 dias antes do lançamento". Quando o ministro os avisou que iria batizar um dos programas como Compromisso Todos pela Educação, acharam muito bom num primeiro momento, mas passaram a se preocupar. Para ela, "há muitos prós e muitos contras" nesta situação.

Apesar disso, ela reforça o fato de o PDE não ser uma política pública do Todos pela Educação. Para ela, "o PDE vai além das cinco metas", ou seja, apesar do ideário ser o mesmo expresso nas cinco metas do TPE, as 28 diretrizes do PDE são diferentes, fazendo com que o PDE seja um plano executivo de governo, que obrigatoriamente é muito mais detalhado.

Para Milú Villela e Luis Norberto Pascoal, a equivalência dos nomes do TPE e do PDE foi ótima, além de ter sido fundamental a escolha do presidente Lula em manter Fernando Haddad no cargo de ministro da Educação. Para Milú Villela, em relação à coincidência de nomes: "Eu particularmente acho isso ótimo porque, primeiro, foi construído junto com a presença do ministro e, depois, porque nós só chegaremos na ponta se existir vontade pública".

Para Maria Auxiliadora Seabra Rezende, ex-secretária de Educação Estadual de Tocantins, o fato de o PDE ter o mesmo nome do movimento veio do próprio nascimento do TPE, que nasceu de forma colaborativa, "articulado com Consed, Undime e MEC". Para ela, "esta colaboração tem como exemplo o PDE”, que foi a incorporação pelo MEC das metas do TPE.

Para os atores externos às duas coalizões, principalmente os acadêmicos, porém, esta semelhança de nomes não causou grandes perturbações. De maneira geral, entenderam que este nome está ligado a conceitos mais gerais, amplamente divulgados no país e no mundo.

Para Maria da Gloria Gohn, professora aposentada da Unicamp e atualmente titular da Uninove, o nome do PDE está ligado a "diretrizes da ONU que já usam o slogan Todos pela Educação". Para ela, este é um "slogan genérico que marca uma época", e ao "falar em Todos pela Educação, é uma forma de diluir todos os movimentos que lutam pela educação, eliminando diferenças político-partidárias".

Mario Sergio Cortella, professor titular da Pontifícia Universidade Católica de São Paulo (PUC-SP), segue a mesma direção ao apontar que este nome "não vem nem do movimento e nem do governo atual, este nome vem de reuniões mundiais que foram feitas e que aconteceram em outros momentos". Ele cita a organização, pela ONU, do Ano Internacional da 
Educação, que levou à discussão do lema Todos pela Educação. Para Cortella, portanto, “este nome não é exclusivo". Ele acha que, por um lado, o movimento TPE vem na direção de algo que está mundialmente estabelecido e, por outro lado, o governo cumpre um de seus compromissos internacionais com as conferências anuais que foram feitas. "O nome não é patenteado, mas é anterior, tanto ao movimento quanto ao atual governo", afirma ele, entendendo que ninguém seja "padrinho dele". Mais do que isso, Cortella não vê problema no fato de o governo aderir "a um nome equivalente ao movimento". Para ele, "que o Estado adira em alguns momentos, isso faz parte das relações da sociedade civil com a sociedade política", o que não faz com que "o movimento seja governo e o governo seja o movimento". A aderência do governo às metas de um dos movimentos é vista por ele não como uma obrigação, mas como uma "coisa inteligente a ser feita", considerando-se que os movimentos "representam partes significativas da sociedade civil".

\section{Considerações finais}

A coincidência entre os nomes do Plano de Metas Compromisso Todos pela Educação e da coalizão Todos pela Educação foi para muitos entrevistados, principalmente ligados à Campanha, uma escolha por parte do governo em privilegiar parte da sociedade civil. Neste sentido, poderíamos entender esta situação como o resultado da dominância de uma coalizão, no caso o TPE, sobre a Campanha Nacional pelo Direito à Educação.

Em nossa opinião, porém, entendemos que, pelo fato de o ministro da Educação, Fernando Haddad, ter participado, desde o início, das discussões desta nova coalizão, a escolha do nome surgiu como resultado de um projeto que foi elaborado de maneira colaborativa. $\mathrm{O}$ lançamento do PDE realmente não conseguiu incluir todos os atores em sua definição, buscando incluí-los apenas na implementação das medidas. Houve, neste sentido, uma reversão de um processo que deveria ter garantido a presença de toda a sociedade civil durante a sua elaboração, assim como ocorreu com o PNE. O momento de troca de cargos nos ministérios, porém, foi decisivo para que o governo lançasse este plano sem a realização prévia de uma Conferência Nacional de Educação, buscando reverter este processo depois que o plano havia sido anunciado, debatendo-o ao longo de 2007.

Dado o contexto em que o PDE foi lançado, fica evidente a questão formulada por Sabatier e Jenkins-Smith (1993) de que é preciso que haja uma oportunidade para que as coalizões possam agir. O momento político, assim, abriu uma janela de oportunidade, como trabalhado por Kingdon (1995), para que uma das coalizões conseguisse uma maior interlocução com o governo. E, neste sentido, é importante refletir sobre os diferentes recursos que cada uma das coalizões possui e as reais capacidades de se fazerem presentes quando esta janela de oportunidade se abre.

Como apontado por Sabatier e Jenkins-Smith (1993), as coalizões possuem recursos (financeiros, humanos, de tempo etc.) que diferenciam seu poder de barganha e influência política. Para alguns autores, como Marques (1997) e Lindblom (1981), os grandes grupos 
privados e empresários são atores privilegiados no processo, considerando-se seu poder econômico e sua posição de destaque na sociedade. Por outro lado, entendemos, assim como proposto por Migdal, Kohli e Shue (1994), que a ação política e a influência de um grupo social não são completamente previsíveis de acordo com a posição deste grupo na estrutura social, dado que há outros fatores que precisam ser igualmente analisados.

Neste sentido, o TPE, ao articular, entre outros atores, grandes grupos empresariais, mostra-se um interlocutor privilegiado no debate com o governo. O TPE detém maior abertura para o diálogo com o Poder Executivo, com grupos privados e com a mídia, decorrente do poder econômico que está representado nesta coalizão. Por outro lado, na Campanha existe um maior acúmulo do conhecimento técnico (maior entendimento em relação à educação e à política de educação), em decorrência da própria formação de seus membros, além de um maior poder de mobilização em relação ao TPE. São recursos distintos, que vão determinar diferentes formas de ação.

Cobb e Elder (1995) introduzem na discussão a questão do relacionamento dos agentes estatais com os demais atores. Para eles, um tomador de decisão pode estar pessoalmente "endividado" ou identificar-se mais fortemente com um determinado grupo, alguns grupos podem estar localizados mais estrategicamente na estrutura social ou econômica, possuir mais recursos do que outros, ser socialmente mais reconhecidos, entre muitos outros fatores. Neste ponto, a identificação do ministro Fernando Haddad deveria ser com os dois grupos porque, se por um lado ele possui uma formação política ligada a grupos de esquerda, sua trajetória pessoal está mais ligada a grupos privados, como indicado por Daniel Cara.

Por fim, merece destaque o aprendizado gerado pela presença destas duas coalizões e para os benefícios que ambas trazem para o campo. O cenário formado pelas duas coalizões enriquece o debate, justamente porque cada uma delas aponta diferentes formas para o alcance de uma educação de qualidade.

Deste modo, por mais que a educação tenha um importante espaço no discurso e seja cada vez mais defendida, vê-se que ainda não há uma coalizão suficientemente forte para que as políticas públicas sejam efetivamente desenhadas e implementadas - e ainda não há o requerido distanciamento para esta análise. O reconhecimento de que a educação é um problema nacional, evidenciado pelos inúmeros estudos sobre o assunto, portanto, não faz com que, automaticamente, a educação vire pauta prioritária para o governo. É preciso que haja, além do reconhecimento técnico, uma força política capaz de levar o problema adiante, incluindo-o na agenda.

O surgimento de uma nova coalizão, com a inclusão de novos atores, pode significar uma ampliação dos debates na área, garantindo que a educação ganhará mais espaço na agenda governamental. A presença destas duas coalizões no campo educacional, assim, deve ser vista com grande esperança, porque o embate entre estas duas coalizões e sua união em determinados momentos pode significar que a educação, a médio e longo prazo, pode tornar-se um assunto que efetivamente mereça atenção do governo, com políticas que visem à reversão dos indicadores atuais. 


\section{Referências}

BRASIL. Discurso do presidente da República, Luiz Inácio Lula da Silva, na cerimônia de assinatura dos atos normativos do Plano de Desenvolvimento da Educação (2007). Disponível em: <www. biblioteca.presidencia.gov.br>. Acesso em: 14 jan. 2008.

COBB, Roger; ELDER, Charles. Issues and agendas. In: THEODOULOU, Stella; CAHN, Matthew. Public policy: the essential readings. Upper Saddle River, NJ: Prentice Hall, 1995. cap. 12, p. 96-105.

COHEN, Jean. Sociedade civil e globalização: repensando categorias. Dados - Revista de Ciências Sociais, Rio de Janeiro, v. 46, n. 3, p. 419-459, 2003.

EVANS, Peter; RUESCHEMEYER, Dietrich; SKOCPOL, Theda. Bringing the State back in. Cambridge: Cambridge University Press, 1985.

GOHN, Maria da Glória. Teoria dos movimentos sociais: paradigmas clássicos e contemporâneos. São Paulo: Loyola, 2006.

GRINDLE, Merilee; THOMAS, John. Public choices and policy change: the political economy of reform in developing countries. Baltimore: The John Hopkins University Press, 1991.

INEP. Instituto Nacional de Estudos e Pesquisas Educacionais Anísio Teixeira. Disponível em: <http://portalideb.inep.gov.br>. Acesso em: out. 2011.

KINGDON, John. Agendas, alternatives and public choices. Nova York: Harper College Publishers, 1995.

LINDBLOM, C. O processo de decisão política. Brasília: Ed. Universidade de Brasília, 1981.

MALINI, Eduardo. O consenso como ponto de partida? Uma análise dos papéis desempenhados pelos atores participantes na formulação do Plano de Desenvolvimento da Educação. Dissertação (mestrado em educação) — Universidade Federal de Juiz de Fora, Juiz de Fora, 2009.

MARQUES, Eduardo. Notas críticas à literatura sobre Estado, políticas estatais e atores políticos. BIB — Revista Brasileira de Informação Bibliográfica em Ciências Sociais, n. 43, p. 67-102, 1997.

MIGDAL, Joel; KOHLI, Atul; SHUE, Vivienne. State power and social forces: domination and transformation in the Third World. Cambridge: Cambridge University Press, 1994.

MUNCK, Gerardo. Formação de atores, coordenação social e estratégia política: problemas conceituais do estudo dos movimentos sociais. Dados - Revista de Ciências Sociais, Rio de Janeiro, v. 40, n. 1, 1997.

RITCHIE, Jane; LEWIS, Jane. Qualitative research practice: a guide for social science students and researchers. Londres: Sage Publications, 2003.

SABATIER, Paul. Toward better theories of the policy process. Political Science and Politics, v. 2, n. 24, p. 147-156, 1991.

Rev. Adm. Pública - Rio de Janeiro 47(3):567-586, maio/jun. 2013 
SABATIER, Paul; JENKINS-SMITH, Hank. Policy change and learning: an advocacy coalition approach. Colorado: Westview Press, 1993.

SIMIELLI, Lara. Coalizões em educação no Brasil: a pluralização da sociedade civil na luta pela melhoria da educação pública. Dissertação (mestrado em administração pública e governo) — Escola de Administração de Empresas de São Paulo, Fundação Getulio Vargas, São Paulo, 2008.

TODOS PELA EDUCAÇÃO. História, conquistas e visão de futuro: edição comemorativa do primeiro ano do compromisso TODOS PELA EDUCAÇÃO. São Paulo: Todos pela Educação, 2007.

Lara Elena Ramos Simielli é doutoranda em administração pública e governo na Escola de Administração de Empresas de São Paulo da Fundação Getulio Vargas (FGV-EAESP) e oficial de projetos no setor de educação da Unesco (Organização das Nações Unidas para a Educação, a Ciência e a Cultura). E-mail: lasimielli@yahoo.com.br. 